\title{
3D assessment of fracture of sand particles using discrete element method
}

\author{
M. B. CIL* and K. A. ALSHIBLI*
}

\begin{abstract}
Shearing or compression of granular materials causes particles to translate and rotate relative to each other, interlock or fracture depending on their mineralogy, morphology, porosity, applied stresses and boundary conditions. Conventional soil plasticity theories consider mainly the stress level and density to predict soil failure and ignore the influence of particle fracture. However, recent research has shown that there is a strong relationship between granular particle fracture and plastic yielding and hardening. In this study, the fracture of individual silica sand particles was modelled by adopting the bonded particle model concept within the framework of the discrete element method (DEM). Individual threedimensional (3D) particles were generated as an agglomerate of a large number of small spherical subparticles that were connected by parallel bonds that resist moment and tension at contact points. The tensile strength variation observed when testing natural silica sand was achieved by changing the shape of the particle, the size and distribution of the spherical sub-particles and their bond strength. The onset and propagation of cracks through the particle were investigated using DEM and verified experimentally using 3D synchrotron micro-computed tomography images of sand. The behaviour across the scale from a single particle to a laboratory-size specimen is also presented and discussed.
\end{abstract}

KEYWORDS: compressibility; discrete-element modelling; fractals; particle crushing/crushability; sands

ICE Publishing: all rights reserved

\section{INTRODUCTION}

Fracture of particles plays an important role in determining the constitutive behaviour and deformation characteristics of granular materials. Plastic deformation of granular materials has been modelled within the framework of frictional energy dissipation and hardening plasticity to describe the constitutive behaviour of soils (e.g. Roscoe et al., 1958; Roscoe \& Burland, 1968). However, classical soil plasticity models do not capture the change in the constitutive behaviour of granular materials since they ignore the clastic nature of particles. Particle breakage alters the dilatant behaviour of sands at high stresses (Bolton, 1986) and leads to the development of a linear normal compression line in onedimensional (1D) compression experiments (Coop \& Lee, 1993; McDowell \& Bolton, 1998). It is also directly correlated to plastic yielding (McDowell \& Bolton, 1998; McDowell \& Harireche, 2002b) and a major contributor to the accumulation of strain in cyclic loading (Harireche \& McDowell, 2003). Furthermore, particle fracture influences the location of the critical state line (Cheng et al., 2005).

Most laboratory experiments focus on investigating particle fracture using relatively large specimens that are suitable for characterising the bulk behaviour of granular materials. There are still experimental limitations on measuring fracture of small individual sand particles. As a result, the discrete element method (DEM) can serve as an excellent tool to better understand the influences of particle fracture on soils engineering behaviour. Most DEM models use incompressible rigid discs or spheres to represent soil particles, which cannot capture the plastic behaviour, critical state and stress-dilatancy relationships (Robertson \&

Manuscript received 4 May 2012; first decision 24 May 2012; Accepted 1 August 2012

Published online at www.geotechniqueletters.com on 28 September 2012.

*Department of Civil \& Environmental Engineering, University of Tennessee, Knoxville, TN, USA
Bolton, 2001). In the literature, individual particle fracture has been simulated using the DEM by treating the particle as an agglomerate of bonded spherical sub-particles (Robertson \& Bolton, 2001; McDowell \& Harireche, 2002a; Cheng et al., 2003 ) or by substituting individual rigid particles with a group of particles based on a certain failure criterion (Tsoungui et al., 1999; Lobo-Guerrero and Vallejo, 2005). McDowell \& Harireche (2002a, 2002b) and Cheng et al. (2003) demonstrated that single sand particles can be modelled in the DEM using an agglomerate of spherical sub-particles bonded by contact bonds to capture the stress variation of single particle fracture, the uniaxial compression of granular assembly, and the plastic hardening and yielding of sand. The agglomerate is generally composed of regularly packed spheres that are linked by contact bonds and the variation in tensile strength of crushable particle was achieved by a random removal of about $20-50 \%$ of the sub-spheres to mimic experimental variation of tensile strength. The tensile failure mode that causes particle fracture was not investigated in these studies and was not verified by experimental measurements.

Potyondy \& Cundall (2004) proposed a numerical distinct element model called the bonded particle model (BPM) to model the fracture behaviour of rocks. The rock was represented by a dense packing on non-uniform-sized circular or spherical particles bonded at their contact points. In the work of Potyondy \& Cundall (2004), the BPM was applied to two-dimensional (2D) and threedimensional (3D) biaxial, triaxial and Brazilian tests and for $2 \mathrm{D}$ tunnel simulation. In this paper, the fracture of individual silica sand particles was modelled in 3D DEM as an agglomerate of a large number of non-uniform-sized spherical sub-particles bonded together according to the BPM.

\section{EXPERIMENTAL WORK}

Jaeger (1967) studied the crushing of rocks between two 
platens and proposed the following expression to calculate the tensile strength of particles

$$
\sigma=\frac{F}{d^{2}}
$$

where $\sigma$ is the characteristic tensile strength, $F$ is the compressive force at failure and $d$ is the initial diameter of the particle. Voo (2000) and McDowell (2002) showed that the Weibull statistical distribution captures the experimental variation of tensile strength of silica sand very well. The survival probability $P_{\mathrm{s}}(d)$ of a particle is expressed as (Weibull, 1951)

$$
P_{\mathrm{s}}(d)=\exp \left[-\left(\frac{\sigma}{\sigma_{0}}\right)^{m}\right]
$$

where $\sigma_{0}$ is the characteristic tensile stress corresponding to a $37 \%$ survival probability and $m$ is the Weibull modulus. $\sigma_{0}$ is determined by plotting $\ln \left[\ln \left(P_{\mathrm{s}}\right)\right]$ versus random values of $\ln (\sigma)$.

In this paper, single particle fracture experiments were conducted on 87 particles of ASTM 20-30 Ottawa sand, a natural silica sand with well-rounded particles and with a grain size between US sieves \#20 $(0.599 \mathrm{~mm})$ and \#30 $(0.853 \mathrm{~mm})$. In addition, three 1D compression experiments were conducted on a sand column composed of three sand particles using a special test cell. The sand particles were poured inside a $1 \mathrm{~mm}$ cylindrical hole at the centre of a $15 \mathrm{~mm}$ acrylic cylindrical mould and were compressed at a constant displacement rate. A larger specimen (here called the 'laboratory-size specimen') with a diameter of $4.32 \mathrm{~mm}$ and height of $6.41 \mathrm{~mm}$ of the same sand was also tested under 1D compression. Multiple synchrotron microcomputed tomography (SMT) scans were acquired on the specimens using beam-13D of GSECARS sector of the Advanced Photon Source (APS), Argonne National Laboratory, Illinois, USA. Figure 1 shows axial crosssections of the SMT images of individual sand grains and the three columns of sand experiments as an example.

\section{DEM SIMULATIONS}

DEM simulations of granular particle fracture were performed using the commercial code PFC3D, which adopts the distinct element method of Cundall \& Strack (1979). Sand particles were represented by an agglomerate of non-uniform-sized spherical sub-particles bonded together at their contact points by parallel bonds that act as a cementing material which can transfer force and moment between adjacent spheres. Strong force chains carry the majority of the load in the BPM. The densely packed assembly of spherical sub-particles was initially generated in a spherical shell element according to a size distribution defined by the maximum $\left(R_{\max }\right)$ and minimum $\left(R_{\min }\right)$ spherical sub-particles radii. Then, the assembly was subjected to a relatively low isotropic compression by increasing the spherical sub-particles' radii uniformly. Particles that have two or less contacts (except particles close to boundaries) were expanded and moved until a minimum of three contacts was achieved and parallel bonds were assigned to all contact points. All bonds between spherical sub-particles in each agglomerate have the same strength, which was chosen randomly from the normal distribution function defined by strength and the associated standard deviation values listed in Table 1.

Each agglomerate represents a single sand particle. It was stabilised by a cycling process under gravity to reach equilibrium and was then compressed between two parallel platens at a constant velocity up to fracture. The loading rate was determined by running simulations at different displacement rates to eliminate the effect of loading rate. The fastest displacement rate of $0.02 \mathrm{~m} / \mathrm{s}$ that did not influence the material strength was selected as the optimum displacement rate. Figure 2 shows compressive load versus displacement of four DEM simulations and three example agglomerate configurations. The compressive load increases linearly up to a major fracture of the particle when it splits into small fragments. As a result, the load drops and increases in some cases, which is attributed to asperity damage and bond breakage at the end platen-particle contacts. Asperity fracture resulted in a significant load reduction and multiple peaks in some DEM simulations due to stress concentration in one or two spherical sub-particles, which greatly influenced the fracture mode of the agglomerate. This issue was minimised by increasing the number of spherical sub-particles, which resulted in more contact points at the platen-agglomerate contact zone.

Compared with the published literature mentioned in the Introduction, a more realistic approach was adopted in this paper where the minimum diameter of spherical subparticles, the bonding strength between spherical subparticles, the shape and fabric of the agglomerate were altered in 40 different DEM simulations to mimic the mechanical and physical behaviour of sand particles. Initially, the sensitivity of the model to each microparameter was examined by performing a series of simulations with varying parameter values. Particle size and packing density of spherical sub-particles have minor effects on the behaviour of the agglomerate. Particle elastic modulus $\left(E_{\mathrm{c}}\right)$ and cement elastic modulus $\left(\bar{E}_{\mathrm{c}}\right)$ were chosen as $70 \mathrm{GPa}$ based on laboratory experiments and the literature (Azom, 2012). The mean normal bond strength $\sigma$ is directly proportional to $\sigma_{0}$ and its standard deviation, and mainly governs the variation of tensile strength (m modulus in Weibull distribution). Shear bond strength $\tau$ has relatively negligible influence on material behaviour; however, both values were assumed equal to enable normal and shear bond failure. The standard deviation of material strength was set to zero and mean bond strength values of 625 and $325 \mathrm{MPa}$ reproduced the highest and lowest tensile strengths measured in the experiments. The bond strength was assigned through a random number generator using a mean bond strength of $475 \mathrm{MPa}$ with a standard deviation of $150 \mathrm{MPa}$. The friction coefficient $\mu$ was set to $0 \cdot 5$. Table 1 presents a summary of the DEM simulation parameters. Weibull probability distributions of laboratory experiments on individual sand particles and DEM simulations are depicted in Fig. 3, which shows good agreement between the two results. The $37 \%$ characteristic tensile strength of sand particles was 131.5 and $137.9 \mathrm{MPa}$ in the DEM and laboratory tests, respectively. Referring to Fig. 3, the data did not fit the linear model well at low tensile stress. When a large number of particles are tested, few particles may have a low tensile stress and the exponential variation of the $y$-axis leads to a low-strength tail in the distribution.

\section{SAND FRACTURE BEHAVIOUR ACROSS THE SCALE}

Additional 1D compression DEM simulations on a column composed of three particles and a relatively larger laboratory-size specimen were conducted in order to further verify the accuracy of the model, investigate the fracture behaviour of sand across the scale and examine the contact force interaction between agglomerates. Rigid spherical particles were generated according to the configuration of the particles in the SMT experiment (Fig. 1(c)). The SMT images shown in Fig. 1 represent cross-sections 


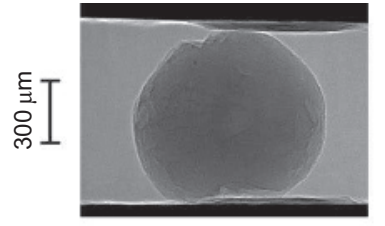

$\Delta z=0 \mu \mathrm{m}$

Load $=0 \mathrm{~N}$

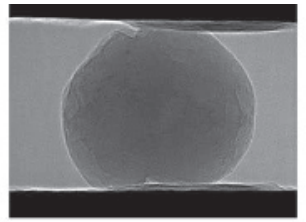

$\Delta z=39 \cdot 4 \mu \mathrm{m}$

Load $=41 \mathrm{~N}$

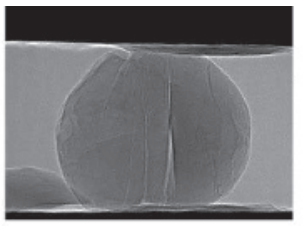

$\Delta z=97 \cdot 2 \mu \mathrm{m}$

$\operatorname{Load}=23 \mathrm{~N}$

(a) Single particle without lateral boundary

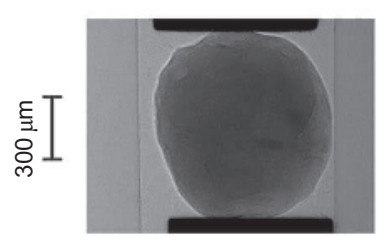

$\Delta z=0 \mu \mathrm{m}$ Load $=0 \mathrm{~N}$

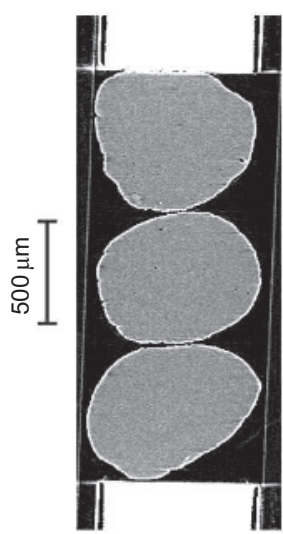

$\Delta z=0 \mu \mathrm{m}$ Load $=0 \mathrm{~N}$

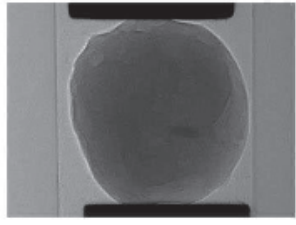

$\Delta z=31 \cdot 7 \mu \mathrm{m}$

Load $=54 \mathrm{~N}$

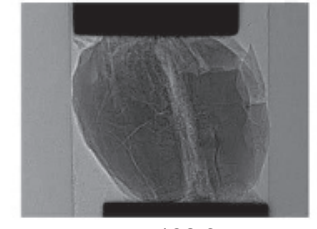

$\Delta z=108.9 \mu \mathrm{m}$

Load $=15 \mathrm{~N}$

(b) Single particle with lateral boundary

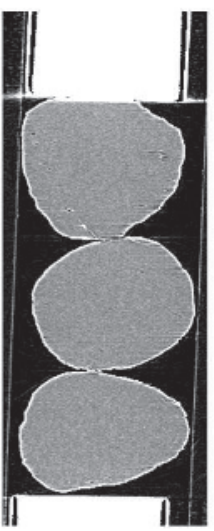

$\Delta z=79 \cdot 2 \mu \mathrm{m}$

Load $=48 \mathrm{~N}$

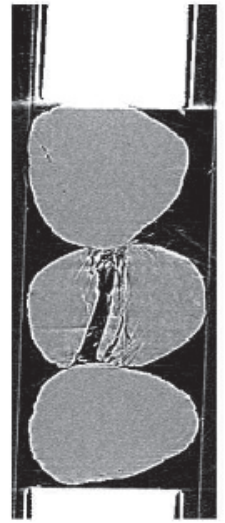

$\Delta z=148.5 \mu \mathrm{m}$ Load $=22 \mathrm{~N}$

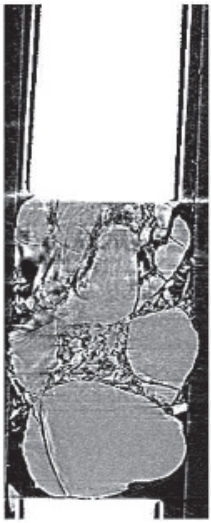

$\Delta z=560 \mu \mathrm{m}$ Load $=88 \mathrm{~N}$

(c) Experiment I: three particle column

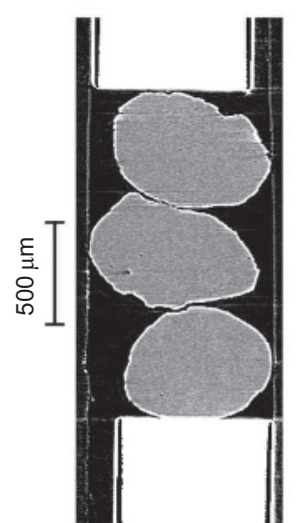

$\Delta z=0 \mu \mathrm{m}$ Load $=0 \mathrm{~N}$

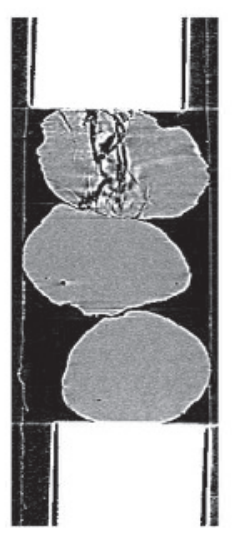

$\Delta z=69 \cdot 3 \mu \mathrm{m}$

Load $=22 \mathrm{~N}$

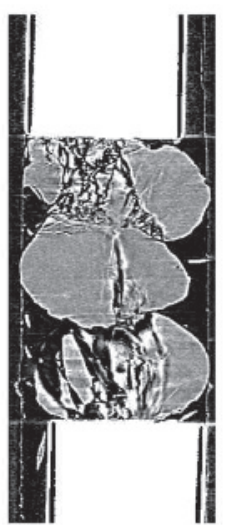

$\Delta z=227 \cdot 7 \mu \mathrm{m}$ Load $=30 \mathrm{~N}$

(d) Experiment II: three particle column

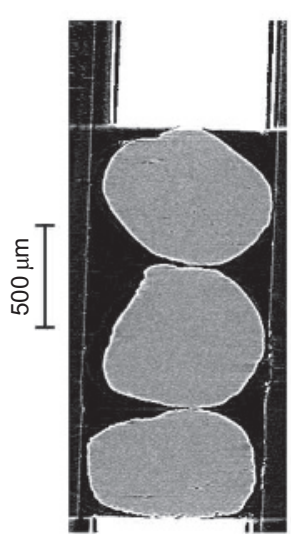

$\Delta z=0 \mu \mathrm{m}$

Load $=0 \mathrm{~N}$

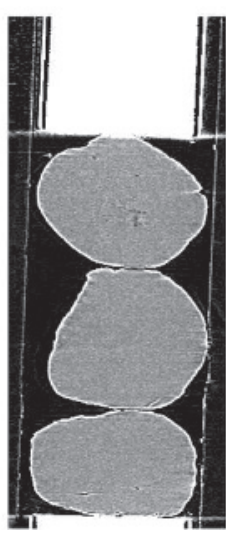

$\Delta z=39 \cdot 6 \mu \mathrm{m}$ Load $=32 \mathrm{~N}$

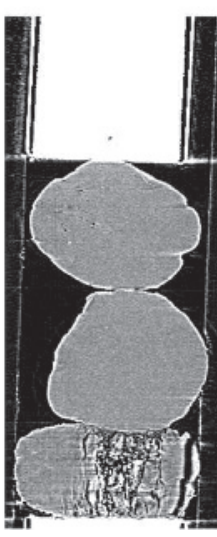

$\Delta z=158 \cdot 4 \mu \mathrm{m}$

Load $=53 \mathrm{~N}$

(e) Experiment III: three particle column

Fig. 1. Axial sections of 3D SMT images of two single particles and three 1D compression experiments at progressive load levels ( $\Delta Z$ represents the change in height of sand column)

of 3D images. Taking different sections of the 3D image of the sand columns reveals that some sand particles are not circular but are rather close to ellipse geometry because the cross-sections do not pass through the centre of the particle. However, Ottawa sand particles are still very close to a spherical shape. Changing the location of the cross-section will influence the shape of the $2 \mathrm{D}$ section of the $3 \mathrm{D}$ particle.

Each rigid DEM particle was substituted by an arbitrarily rotated agglomerate that was generated according to the 
Table 1. Values of parameters used in DEM model (see Potyondy \& Cundall (2004) for further explanation of parameters)

\begin{tabular}{l|c}
\hline Parameter & Value \\
\hline Diameter of agglomerate, $D$ & $0 \cdot 6-0 \cdot 8 \mathrm{~mm}$ \\
Wall stiffness & $2 \times 10^{7} \mathrm{~N} / \mathrm{m}$ \\
Spherical sub-particle properties & \\
Mass density, $\rho$ & $2650 \mathrm{~kg} / \mathrm{m}^{3}$ \\
Young's modulus, $E_{\mathrm{c}}$ & $70 \mathrm{GPa}$ \\
Minimum radius, $R_{\min }$ & $0 \cdot 035 \mathrm{~mm}, 0 \cdot 045 \mathrm{~mm}$ \\
$R_{\text {max }} / R_{\min }$ & $1 \cdot 2$ \\
Friction coefficient, $\mu$ & $0 \cdot 5$ \\
Normal stiffness/shear stiffness & $2 \cdot 5$ \\
Parallel bond & 1 \\
Bond radius multiplier, $\lambda$ & $70 \mathrm{GPa}$ \\
Young's modulus, $\bar{E}_{\mathrm{c}}$ & $2 \cdot 5$ \\
$\quad$ Normal stiffness/shear stiffness & $475 \mathrm{MPa}$ \\
Mean normal strength, $\sigma$ & $475 \mathrm{MPa}$ \\
Mean shear strength, $\tau$ & $150 \mathrm{MPa}$ \\
Normal and shear strength & \\
standard deviations & \\
\hline
\end{tabular}

saved positions of spherical sub-particles. The specimen was compressed between rigid end platens at a constant velocity of $0.025 \mathrm{~m} / \mathrm{s}$. The load versus displacement relationships for the three sand column experiments and DEM simulations are shown in Fig. 4, which clearly demonstrates that the proposed DEM model has successfully captured the constitutive behaviour and brittle fracture of sand particles. In laboratory experiments, fragments of sand particles can contribute to the resistance to the applied load after a sharp load drop which is manifested in a more pronounced rise in the post-peak load. On the other hand, parallel bonds between spherical sub-particles break progressively and local fractures develop after the initial major fracture in the DEM agglomerate, which results in an oscillatory response after the peak load. Overall, there is good agreement between the DEM simulations and experimental results.

To further investigate the fracture behaviour of sand across the scale, a larger laboratory-size specimen was also scanned and simulated using the DEM (Fig. 5). It is composed of 239 agglomerates and was subjected to 1D compression at a constant velocity of $0.1 \mathrm{~m} / \mathrm{s}$. Initially, the micro-properties that were determined in single crushing simulations were assigned to particles in the assembly. The yielding point of the DEM was found to be less than half

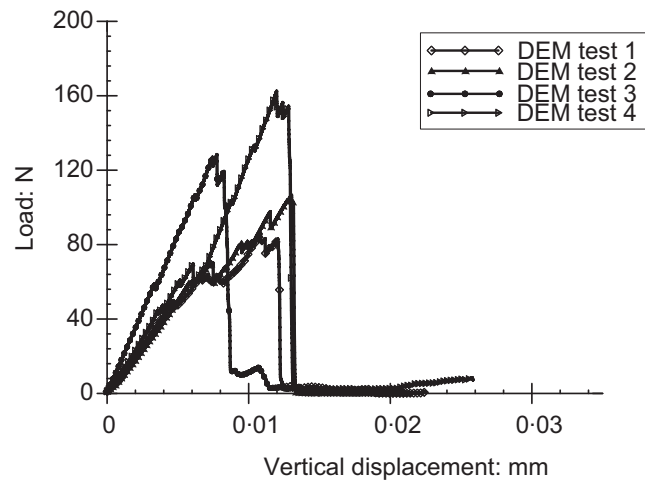

(a)

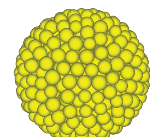

(b)

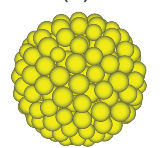

(c)

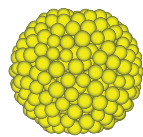

(d)
Fig. 2. (a) Load-displacement relationship of four DEM single particle crushing simulations using $0.6-0.8 \mathrm{~mm}$ agglomerates of sub-spheres with (b) $R_{\min }=0.035 \mathrm{~mm}$, (c) $R_{\min }=0.045 \mathrm{~mm}$, (d) $R_{\min }=0.035 \mathrm{~mm}$ and non-spherical shape

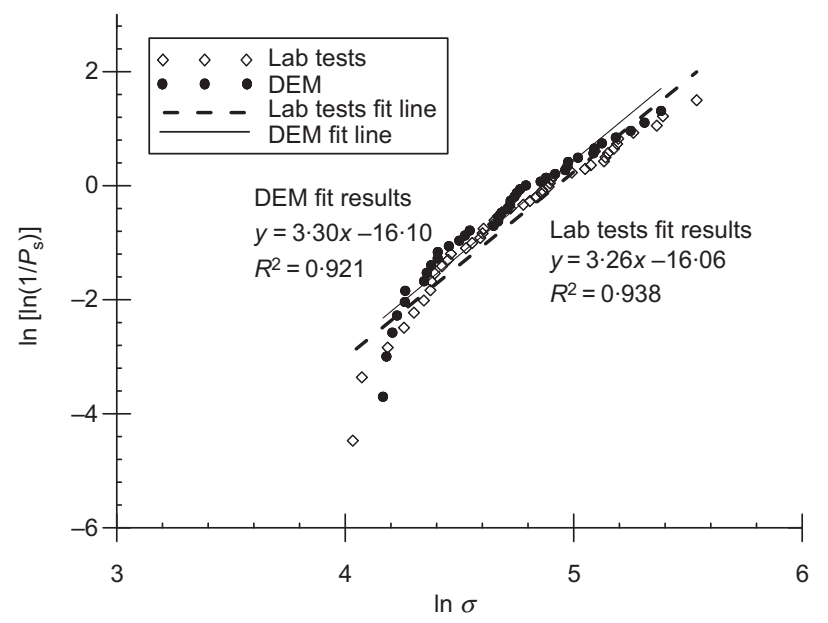

Fig. 3. Weibull probability distribution for individual silica sand laboratory measurements and DEM simulations (40 simulations)

that of a similar laboratory experiment (Fig. 5(d)). Then, the DEM simulation of the laboratory-size specimen was repeated after doubling the bond strength in each agglomerate, which produced a good match with the laboratory test results. Such results demonstrated that the DEM model micro-parameter calibrations based on single particle fracture do not reproduce the stress-displacement behaviour at a larger scale because of the variation in real particle geometry, particle interactions, boundary conditions and strong force chains in the laboratory-size specimen.

\section{CRACK ONSET AND PROPAGATION}

When a particle is subjected to an increasing compressive load, a tensile stress is assumed to originate within a plane perpendicular to the loading direction. Diametric compression of the particle leads to a stress concentration at the contact points, which is assumed as the flaw initiation zone. In order to investigate this crack formation hypothesis, SMT scans of single particle and 1D compression experiments were examined as the load was increased (Figs 1 and 5). The results clearly show that particle breakage was initiated along the plane that connects the two contact points of the particle with adjacent particles. A few single particles and three similar 1D compression experiments

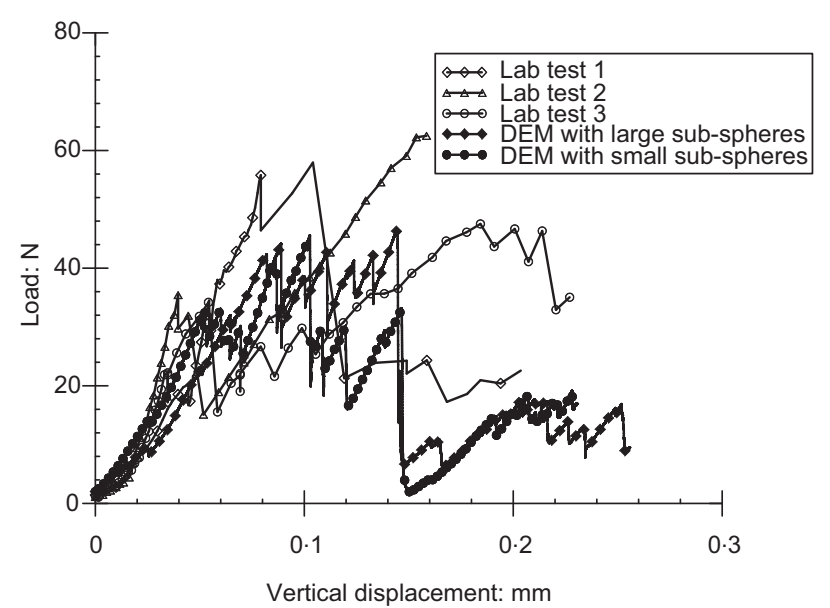

Fig. 4. Laboratory and DEM results of $1 \mathrm{D}$ compression on column of three sand particles 


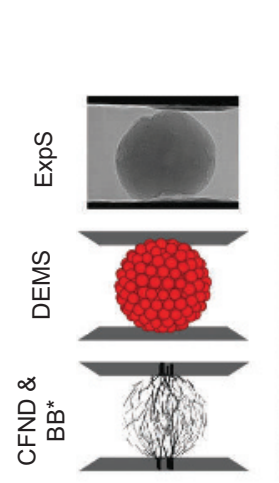

$(0,0)$

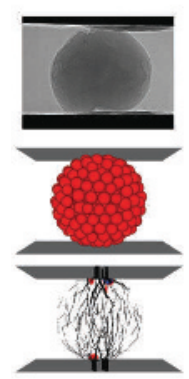

$(7,1)$

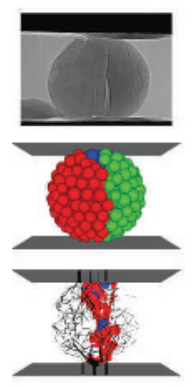

$(95,11)$

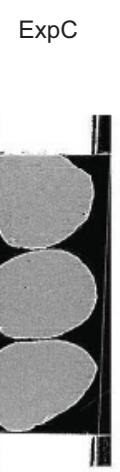

DEMC CFND \&

$\mathrm{BB}^{*}$
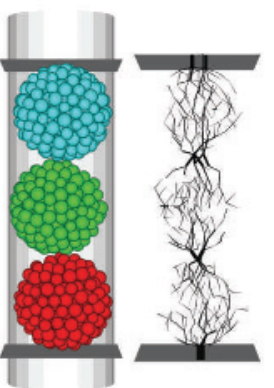

$(0,0)$

(a)
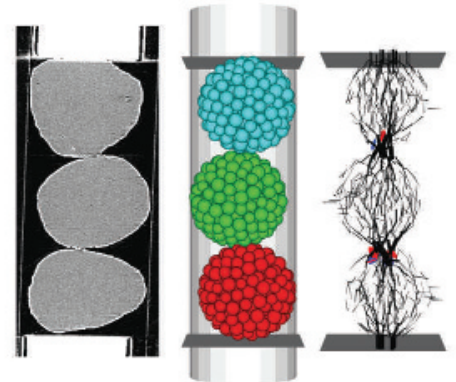

$(7,6)$

(b)
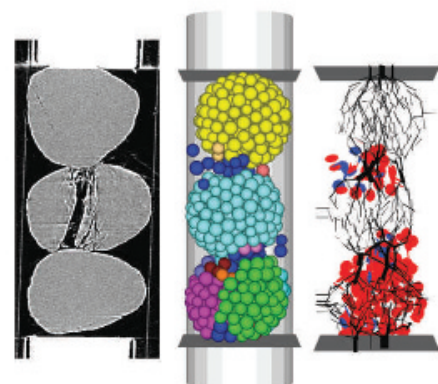

$(221,41)$
ExpL**
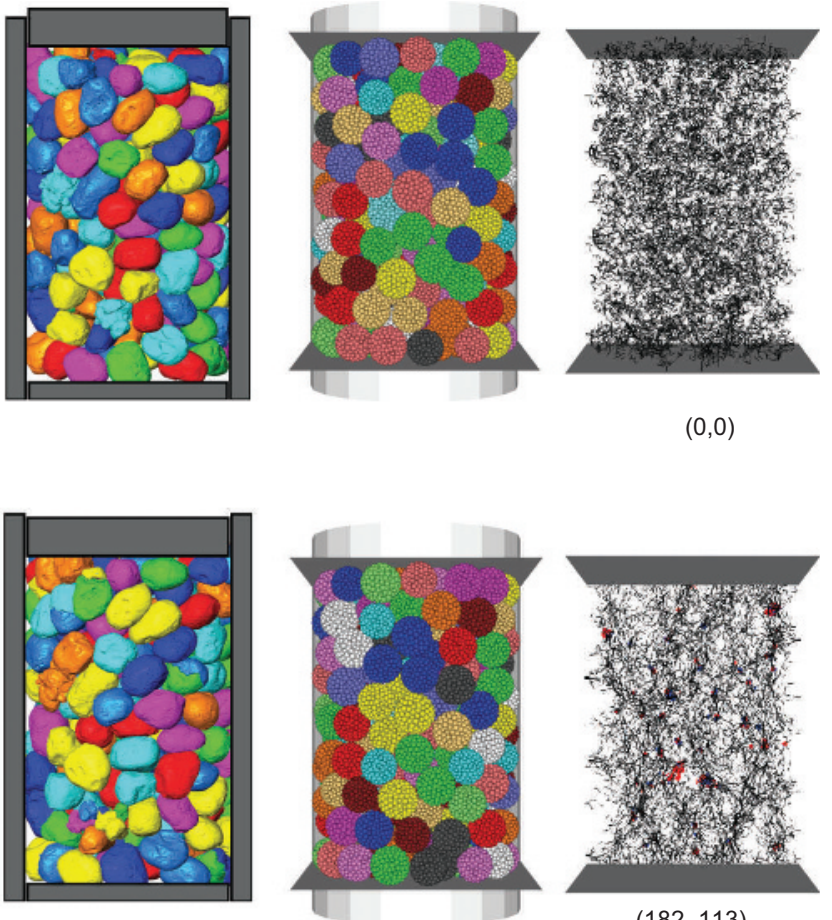

$(182,113)$

CFND \&

$\mathrm{BB}^{*}$
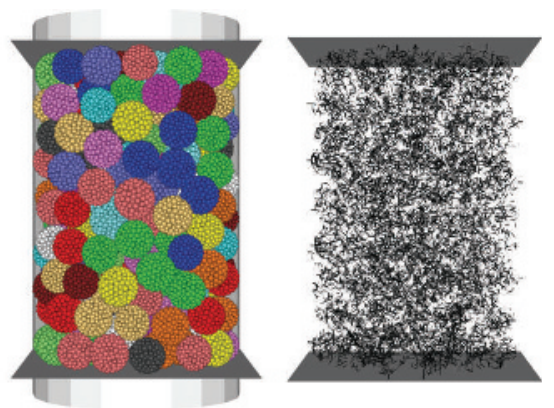

$(0,0)$
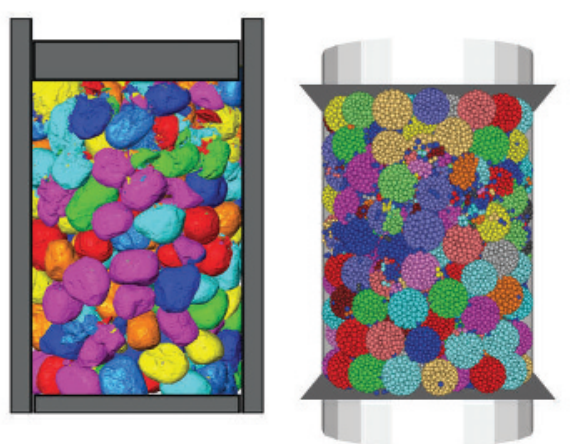

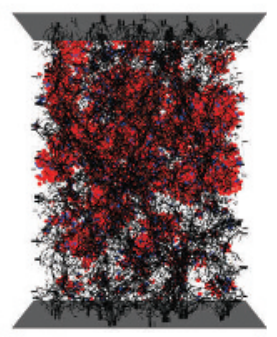

(12549, 2881)

(c)

Scale increase from particle level to laboratory specimen size

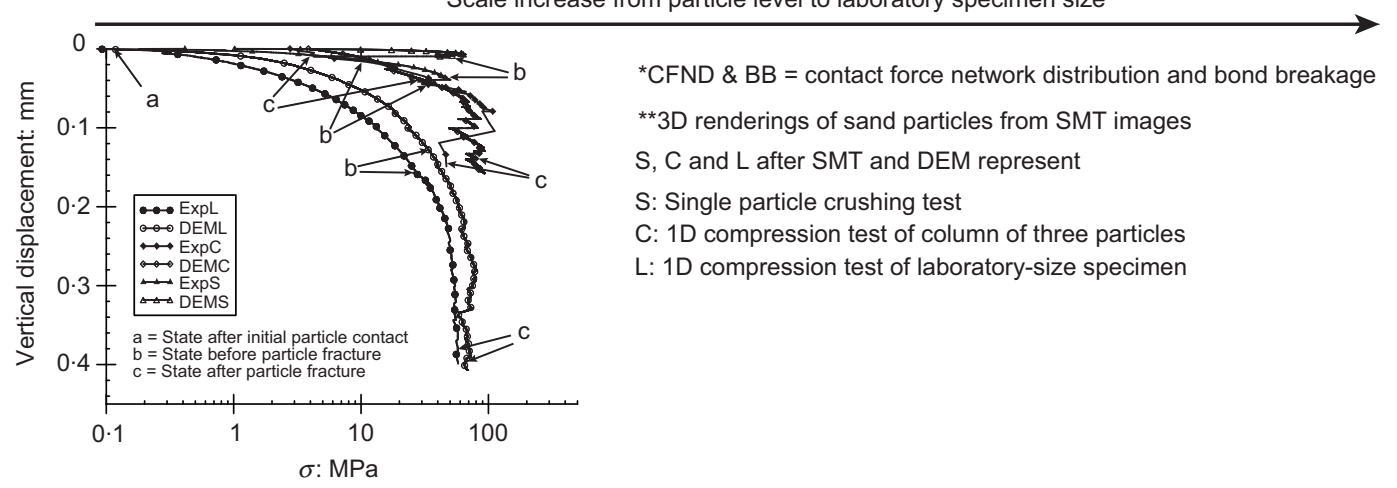

(d)

Fig. 5. SMT and DEM images of single particle, column of three particles and laboratory-size compression tests at different load levels. (a) State after initial particle contact. (b) State before particle fracture. (c) State after particle fracture. Numbers in parenthesis represent tensile (red) and shear (blue) bond breakages as (tensile, shear). (d) Comparison of responses of experiments and DEM simulations for single particle, column of particles and laboratory-size specimen

were performed and scanned using SMT and the particles fractured via a brittle failure surface defined by the contact force direction as seen in Fig. 1. This visualisation demonstrates that the major crack mainly initiates from the compressive contact points, grows parallel to the plane that connects the contact points and eventually leads to 
particle breakage. The SMT images of single particle fracture (e.g. Fig. 1(a)) show that silica sand fails via major splits with no asperity damage.

SMT images provide valuable images of the crack formation mechanism experimentally. However, they do not provide any information about the interior stress distribution within sand particles. Therefore, the DEM was used as a tool to shed light on the tensile stress failure of compression-induced crack propagation. Initiation and propagation of the damage within individual sand particles was examined by tracking the bond breakage in the DEM agglomerates. The number and locations of tension and shear cracks were monitored during the compression of agglomerates in different specimen sizes and the evolution of the bond breakage as the load increases is depicted in Fig. 5. When the load increases, the bond between spherical subparticles breaks mainly by tensile and shear stresses that are concentrated in a plane parallel to the loading direction. The number of cracks in the agglomerate increases as load increases. Tensile cracks (shown in red in Fig. 5) are the dominant type of cracks when compared with shear cracks (shown in blue in Fig. 5). Almost all cracks are parallel to one other and are concentrated along the plane of tensile strength in single particle crushing DEM simulations. A similar failure mode was observed in the SMT image of the single particle fracture experiment (e.g. Fig. 5(a)).

A similar crack mechanism was also observed in threeparticle sand column compression, but the boundary walls slightly change the orientation of crack distribution. The $1 \mathrm{D}$ compression of 239 agglomerates reveals the interaction of clastic particles within the particulate assembly. The cracks mainly initiate at the contacts of agglomerates to form force chains that resist the majority of the axial load. When a particle fractures, the number of bond breakages increases rapidly, force chains collapse and new force chains develop. The onset and evolution of the cracks in Fig. 5 validate the tensile failure theory that governs granular particle breakage under compressive loads and explains the complex loading mechanism and particle crushing characteristics in different scales.

\section{SUMMARY AND CONCLUSIONS}

A new DEM approach is proposed to simulate the fracture behaviour of silica sand. Agglomerates of spherical subparticles were generated according to the BPM and successfully captured the elastic behaviour, brittle particle breakage, and onset and progression of cracks. The proposed model offers significant improvements to capture the fracture of sand by incorporating material parameters that account for variations in experimental tensile strength. The fracture mechanics of sand particles under compression was characterised experimentally using 3D SMT images for the first time at the particle micro-scale. Silica sand particles fail in tension through a plane defined by the contact points of the particle with adjacent particles. The investigation of particle fracture at different specimen scales demonstrated that boundary conditions and particle interactions have significant effects on particle fracture. Moreover, the microproperties of agglomerates based on single particle fracture do not reproduce the stress-displacement behaviour at larger scale because of the variation in real particle geometry, particle interactions, boundary conditions and strong force chains in the laboratory assembly size.

\section{Acknowledgements}

This material is based on work supported by the National Science Foundation under grant no. CMMI-1156436. Any opinions, findings and conclusions or recommendations expressed in this material are those of the authors and do not necessarily reflect the views of the National Science Foundation. The SMT scans presented in this paper were collected using the X-ray Operations and Research Beamline Station 13-BMD at Argonne Photon Source (APS), Argonne National Laboratory; we thank Dr Mark Rivers of APS for help in performing the scans. Use of the APS was supported by the US Department of Energy, Office of Science, Office of Basic Energy Sciences under contract no. DE-AC0206CH11357. The authors also thank Dr David Potyondy of Itasca for his valuable comments and assistance.

\section{REFERENCES}

Azom (2012). http://www.azom.com/article.aspx?articleID $=1114$ (accessed 08/08/2012).

Bolton, M. D. (1986). The strength and dilatancy of sands. Géotechnique 36, No. 1, 65-78.

Cheng, Y. P., Nakata, Y. \& Bolton, M. D. (2003). Discrete element simulation of crushable soil. Géotechnique 53, No. 7, 633-641.

Cheng, Y. P., Bolton, M. D. \& Nakata, Y. (2005). Grain crushing and critical states observed in DEM simulations. Powders and Grains 2005, Proc. 5th Int. Conf. on Micromechanics of Granular Media, Stuttgart, pp. 1393-1397.

Coop, M. R. \& Lee, I. K. (1993). The behaviour of granular soils at elevated stresses. Predictive soil mechanics: Proc. of the Wroth Memorial Symposium, London, pp. 186-198.

Cundall, P. \& Strack, O. (1979). A discrete numerical model for granular assemblies. Géotechnique 29, No. 1, 47-65.

Harireche, O. \& McDowell, G. R. (2003). Discrete element modeling of cyclic loading of crushable aggregates. Gran. Matter 5, No. 3, 147-151.

Jaeger, J. C. (1967). Failure of rocks under tensile conditions. Int. J. Rock Mech. Min. Sci. 4, No. 2, 219-227.

Lobo-Guerrero, S. \& Vallejo, L. E. (2005). DEM analysis of crushing around driven piles in granular materials. Géotechnique 55, No. 8, 617-623.

McDowell, G. R. (2002). On the yielding and plastic compression of sand. J. Japan Geotech. Soc. Soils Found. 42, No. 1, 139-145.

McDowell, G. R. \& Bolton, M. D. (1998). On the micromechanics of crushable aggregates. Géotechnique 48, No. 5, 667-679.

McDowell, G. R. \& Harireche, O. (2002a). Discrete element modelling of soil particle fracture. Géotechnique 52, No. 2, $131-135$.

McDowell, G. R. \& Harireche, O. (2002b). Discrete element modelling of yielding and normal compression of sand. Géotechnique 52, No. 4, 299-304.

Potyondy, D. O. \& Cundall, P. A. (2004). A bonded-particle model for rock. Int. J. Rock Mech. Min. Sci. 41, No. 8, 13291364.

Robertson, D. \& Bolton, M. D. (2001). DEM simulation of crushable grains and soils. Proc. Powder and Grains, Sendai, pp. 623-626.

Roscoe, K. H. \& Burland, J. B. (1968). On the generalized stressstrain behavior of 'wet' clay. In Engineering plasticity. Cambridge: Cambridge University Press, pp. 535-609.

Roscoe, K. H., Schofield, A. N. \& Wroth, C. P. (1958). On the yielding of soils. Géotechnique 8, No. 1, 22-53.

Tsoungui, O., Vallet, D. \& Charmet, J.-C. (1999). Numerical model of crushing of grains inside two-dimensional granular materials. Powder Technol. 105, No. 1-3, 190-198.

Voo, V. K. (2000). Statistics of particle strength in a silica sand. MEng dissertation, University of Nottingham.

Weibull, W. (1951). A statistical distribution function of wide applicability. J. Appl. Mech. 18, No. 3, 293-297.

\section{WHAT DO YOU THINK?}

To discuss this paper, please email up to 500 words to the editor at journals@ice.org.uk. Your contribution will be forwarded to the author(s) for a reply and, if considered appropriate by the editorial panel, will be published as a discussion. 